\title{
Vitreomacular Changes after Intravitreal Gas Injection for Idiopathic Impending or Early Macular Hole: An Optical Coherence Tomography Study
}

\author{
Teck-Boon Tew ${ }^{a}$ Ta-Ching Chen ${ }^{a}$ Chang-Hao Yang ${ }^{a, b}$ Chung-May Yang ${ }^{a, b}$ \\ ${ }^{a}$ Department of Ophthalmology, National Taiwan University Hospital, and b Department of Ophthalmology, College of \\ Medicine, National Taiwan University, Taipei, Taiwan, ROC
}

\section{Keywords}

Vitreomacular traction · Macular hole · Intravitreal gas ·

Optical coherence tomography

\begin{abstract}
Purpose: To study the early changes of vitreomacular microstructure by optical coherence tomography (OCT) after intravitreal gas injection for the treatment of idiopathic impending or early full-thickness macular hole (FTMH). Methods: A retrospective, interventional case series. Results: $A$ total of 21 eyes were included. In the impending macular hole, 8/8 achieved vitreomacular traction (VMT) release, while a macular hole developed in 1 case. On postoperative day 1 , the vitreomacular configuration by OCT showed either a flattening $(n=3)$ or elevation $(n=1)$ pattern. In early FTMH, vitreomacular separation was achieved in 10/13 cases, but macular hole closure was only observed in 3 cases. On postoperative day 1 , only flattening of the vitreomacular configuration was observed $(n=5)$. Enlargement of the macular hole was found in 4 cases. Conclusions: VMT separation can be achieved with intravitreal gas injection by mechanically stretching the posterior vitreous cortex, causing either flattening or steepening of the vitreomacular configuration. However, it did not always result in macular hole closure.
\end{abstract}

(c) 2017 S. Karger AG, Basel

\section{KARGER}

(C) 2017 S. Karger AG, Basel

E-Mail karger@karger.com

www.karger.com/oph

\section{Introduction}

Pars plana vitrectomy (PPV) is the standard treatment for idiopathic full-thickness macular hole (FTMH). For impending macular hole ( $\mathrm{MH}$ ) and early-stage $\mathrm{MH}$, some studies have shown that intravitreal gas might facilitate the separation of vitreomacular traction (VMT) and promote hole closure [1-8]. However, the dynamic changes of the foveal structure after gas injection have not been studied in detail. Recently, ocriplasmin has been shown to induce VMT release and obtain normalization of the macular structure in selected cases [9-12]. After ocriplasmin injection, changes in vitreomacular interface (VMI) and outer sensory retina have been reported [13-17]. Although both intravitreal gas and ocriplasmin are capable of inducing vitreomacular separation, the underlying mechanisms for the release of VMT may be different. In the present study, we described the dynamic changes of the VMI and the outer retinal structures during and after intravitreal gas injection. By studying the early structural changes after gas injection, the mechanisms of how intravitreal gas treatment induces vitreomacular separation may be better understood. 


\section{Methods}

Patients and Baseline Assessment

This is a retrospective, interventional case series that includes consecutive cases of patients who received intravitreal gas injection for the treatment of idiopathic impending $\mathrm{MH}$ or early FTMH at the National Taiwan University Hospital during the period from January 1, 2009 to May 31, 2016. All patients gave full informed consent. The study was in compliance with the Declaration of Helsinki and was permitted by the IRB of the National Taiwan University Hospital.

All patients received comprehensive preoperative examination, including Snellen best-corrected visual acuity (BCVA), slitlamp biomicroscopic examination, and optical coherence tomography (OCT). The OCT was performed under dilated pupils using different commercially available systems, including Cirrus OCT ${ }^{\mathrm{TM}}$ (Carl Zeiss Meditec, Inc., Dublin, CA, USA) or RTVue 100 OCT (Optovue, Inc., CA, USA). All patients had OCT-visible vitreous adhesion to the fovea, causing disruption of macular structure. The staging of FTMH was a modified version of the classification described by Gass [18], based on the recent classification for diseases of vitreomacular interface by the International Vitreomacular Traction Study Group [19], and OCT-based classification system for focal VMT designed by Steel et al. [20]. We defined impending $\mathrm{MH}$ as a focal VMT $(<1,500 \mu \mathrm{m})$ associated with inner foveal cysts, cavitation, with or without outer retinal changes or foveal detachment by OCT, as well as the presence of foveal yellow dot or ring on biomicroscopy. Only those cases that presented with outer retinal dehiscence involving the ellipsoid zone (EZ) and external limiting membrane, or those with foveal detachment were included for the treatment. Those eyes with only inner retinal changes or focal outer retinal abnormality without dehiscence or subretinal fluid were not chosen for gas injection. FTMH was defined as a full-thickness anatomical defect of neurosensory retina tissue from the internal limiting membrane (ILM) to the EZ with or without operculum by OCT. The hole size was measured according to the method described by the International Vitreomacular Traction Study group [20], using the OCT caliper function at the narrowest aperture parallel to the retinal pigment epithelium layer. We chose the maximum measurement in multiple radial scans; the area of operculum was not included in the measurement. FTMHs with focal VMT and hole size of less than $400 \mu \mathrm{m}$ were included. We defined FTMHs with this configuration as stage 2 FTMHs or early FTMHs. The detailed features of the vitreomacular relationship were also recorded, including the area of attachment between the posterior hyaloid and the fovea, the vitreofoveal angle, and the height of retinal elevation. To assess the vitreofoveal angle, we measured the height between the detached posterior hyaloid and the ILM at a distance of $1,000 \mu \mathrm{m}$ from the fovea center after adjusting for the horizontal and vertical magnification of individual OCT instruments, and calculated the vitreofoveal angle by trigonometric functions. The largest angle among nasal, temporal, superior, and inferior aspects was selected as the vitreofoveal angle of the specific case. The height of retinal elevation was defined as the perpendicular distance between retinal pigment epithelium surface and the lowest point of vitreomacular adhesion. Cases that had significant epiretinal membrane with cellophane membrane or striation on the retinal surface on biomicroscopy associated with distinct hyperreflective line on the retinal surface by OCT, pathologic myopia (defined as a spherical equivalent of more than
$-6.00 \mathrm{dpt}$, or an axial length of longer than $26.5 \mathrm{~mm}$ ), retinal vascular diseases, or $\mathrm{MH}$ due to other secondary causes were excluded. Cases were also excluded if peripheral retinal degeneration, including lattice degeneration or retinal breaks, was identified during preoperative examination.

\section{Surgical Procedures}

Pars plana intravitreal injection with $0.10-0.20 \mathrm{ml}$ of $100 \%$ sulfur hexafluoride $\left(\mathrm{SF}_{6}\right)$ or perfluoropropane $\left(\mathrm{C}_{3} \mathrm{~F}_{8}\right)$ using a $27-\mathrm{G}$ needle was performed under topical anesthesia after proper disinfection and anterior chamber paracentesis. The type and volume of gas used for each patient are shown in Tables 1 and 2. Patients were asked to keep a prone or face-down position for at least 5 days after injection. Standard 3-port PPV was arranged if the $\mathrm{MH}$ did not seal.

\section{Follow-Up OCT Assessment}

The first postoperative OCT was performed within 1 month after surgery in all cases. To evaluate the early changes of the VMI, OCT was performed at day 1 postoperatively in certain cases. The VMT was defined as primary release if the posterior hyaloid was completely detached from the macula within 1 month postoperatively. Primary success was defined as primary closure of $\mathrm{MH}$ within 1 month postoperatively, and secondary success was defined as $\mathrm{MH}$ closure spontaneously after 1 month postoperatively, or $\mathrm{MH}$ closure after PPV. For those cases in which VMT did not release on day 1 postoperatively, a change of vitreomacular configuration was recorded. The change of the vitreomacular configuration was defined as flattened if the height of retinal elevation decreased, and was defined as elevated if the height of retinal elevation increased, while any change within $10 \%$ of baseline was defined as insignificant. We also recorded the changes in vitreofoveal angle in the cases of persisted vitreomacular adhesion on postoperative day 1 . Furthermore, other microstructural changes at the vitreomacular interface detected by OCT were also documented, including the presence of subretinal fluid pocket and the restoration of EZ integrity.

\section{Results}

A total of 21 eyes of 20 patients were included (15 females, median age of 58 years, range $47-76$ years). Eight eyes had VMT with impending $\mathrm{MH}$, and the other $13 \mathrm{had}$ early FTMH with diameters of less than $400 \mu \mathrm{m}$. The mean of initial BCVA was $0.80 \pm 0.38 \log$ MAR. The baseline characteristics and clinical data before and after intravitreal gas injections are shown in Tables 1 and 2 .

\section{Impending $M H$}

In this group, VMT release within 1 month after gas injection was noted in all cases, and $\mathrm{MH}$ closure was achieved in 7 of 8 cases (primary success rate: $87.5 \%$ ). FTMH developed in 1 case even after VMT resolution, and was sealed after surgical vitrectomy with ILM peeling. The mean BCVA improved from $0.63 \pm 0.34 \log M A R$
2
Ophthalmologica 2018;239:1-10 DOI: $10.1159 / 000478666$
Tew/Chen/Yang/Yang 
Table 1. Baseline characteristics and clinical data of the patients before and after intravitreal expansile gas injections in the impending $\mathrm{MH}$ group

\begin{tabular}{|c|c|c|c|c|c|c|c|c|c|c|c|c|c|}
\hline \multirow[t]{2}{*}{ Case } & \multirow[t]{2}{*}{$\begin{array}{l}\text { Age, } \\
\text { years }\end{array}$} & \multirow[t]{2}{*}{ Sex } & \multirow[t]{2}{*}{ Eye } & \multirow[t]{2}{*}{$\begin{array}{l}\text { Gas used, } \\
\mathrm{mL}\end{array}$} & \multicolumn{3}{|c|}{ BCVA, logMAR } & \multicolumn{2}{|c|}{$\begin{array}{l}\text { Height of retinal } \\
\text { elevation, } \mu \mathrm{m}\end{array}$} & \multicolumn{2}{|c|}{$\begin{array}{l}\text { Vitreofoveal angle, } \\
\text { degree }\end{array}$} & \multirow{2}{*}{$\begin{array}{l}\text { Primary } \\
\text { VMT } \\
\text { release }\end{array}$} & \multirow{2}{*}{$\begin{array}{l}\text { Primary } \\
\mathrm{MH} \\
\text { closure }\end{array}$} \\
\hline & & & & & $\begin{array}{l}\text { pre- } \\
\text { gas }\end{array}$ & $\begin{array}{l}\text { post- } \\
\text { gas }\end{array}$ & $\begin{array}{l}\text { post- } \\
\text { PPV }\end{array}$ & pre-gas & POD1 & pre-gas & POD1 & & \\
\hline 1 & 63 & $\mathrm{M}$ & OD & $\mathrm{C}_{3} \mathrm{~F}_{8} 0.15$ & 0.30 & 0.05 & $\mathrm{~N} / \mathrm{A}$ & 443 & 320 & 21.8 & $\mathrm{R}$ & Yes & Yes \\
\hline 2 & 52 & $\mathrm{~F}$ & OS & $\mathrm{SF}_{6} 0.2$ & 0.40 & 0.52 & 0.15 & 343 & 351 & 15.6 & 10.8 & Yes & No \\
\hline 3 & 57 & $\mathrm{M}$ & OS & $\mathrm{SF}_{6} 0.2$ & 0.52 & 0.00 & N/A & 300 & 268 & 25.7 & $\mathrm{R}$ & Yes & Yes \\
\hline 4 & 49 & $\mathrm{~F}$ & OS & $\mathrm{C}_{3} \mathrm{~F}_{8} 0.15$ & 0.30 & 0.05 & N/A & 306 & 256 & 28.9 & 3.4 & Yes & Yes \\
\hline 5 & 61 & $\mathrm{~F}$ & OS & $\mathrm{C}_{3} \mathrm{~F}_{8} 0.15$ & 1.30 & 0.05 & N/A & 470 & 490 & 40.5 & 45.1 & Yes & Yes \\
\hline 6 & 54 & $\mathrm{~F}$ & OS & $\mathrm{C}_{3} \mathrm{~F}_{8} 0.2$ & 0.30 & 0.10 & $\mathrm{~N} / \mathrm{A}$ & 254 & 233 & 10.8 & 0.7 & Yes & Yes \\
\hline 7 & 68 & $\mathrm{~F}$ & OS & $\mathrm{C}_{3} \mathrm{~F}_{8} 0.2$ & 1.00 & 0.15 & $\mathrm{~N} / \mathrm{A}$ & 283 & 199 & 16.1 & $\mathrm{R}$ & Yes & Yes \\
\hline 8 & 68 & $\mathrm{~F}$ & OD & $\mathrm{C}_{3} \mathrm{~F}_{8} 0.2$ & 1.00 & 0.15 & N/A & 211 & 200 & 24.8 & $\mathrm{R}$ & Yes & Yes \\
\hline
\end{tabular}

MH, macular hole; BCVA, best-corrected visual acuity; PPV, pars plana vitrectomy; POD1, postoperative day 1; VMT, vitreomacular traction; R, VMT released; N/A, not applicable.

Table 2. Baseline characteristics and clinical data of the patients before and after intravitreal expansile gas injections in the early FTMH group

\begin{tabular}{|c|c|c|c|c|c|c|c|c|c|c|c|c|c|c|}
\hline \multirow[t]{2}{*}{ Case } & \multirow[t]{2}{*}{$\begin{array}{l}\text { Age, } \\
\text { years }\end{array}$} & \multirow[t]{2}{*}{ Sex } & \multirow[t]{2}{*}{ Eye } & \multirow[t]{2}{*}{$\begin{array}{l}\text { Gas used, } \\
\mathrm{mL}\end{array}$} & \multicolumn{3}{|c|}{ BCVA, logMAR } & \multirow{2}{*}{$\begin{array}{l}\text { Hole } \\
\text { size, } \\
\mu \mathrm{m}\end{array}$} & \multicolumn{2}{|c|}{$\begin{array}{l}\text { Height of retinal } \\
\text { elevation, } \mu \mathrm{m}\end{array}$} & \multicolumn{2}{|c|}{$\begin{array}{l}\text { Vitreofoveal } \\
\text { angle, degree }\end{array}$} & \multirow{2}{*}{$\begin{array}{l}\text { Primary } \\
\text { VMT } \\
\text { release }\end{array}$} & \multirow{2}{*}{$\begin{array}{l}\text { Primary } \\
\mathrm{MH} \\
\text { closure }\end{array}$} \\
\hline & & & & & pre-gas & post-gas & $\begin{array}{l}\text { post- } \\
\text { PPV }\end{array}$ & & pre-gas & $\mathrm{POD}^{\mathrm{a}}$ & pre-gas & $\mathrm{POD}^{\mathrm{a}}$ & & \\
\hline 9 & 62 & $\mathrm{~F}$ & OS & $\mathrm{C}_{3} \mathrm{~F}_{8} 0.2$ & 1.30 & 0.70 & N/A & 120 & 428 & $\mathrm{~N} / \mathrm{A}$ & 17.3 & N/A & Yes & Yes \\
\hline 10 & 58 & $\mathrm{~F}$ & OD & $\mathrm{C}_{3} \mathrm{~F}_{8} 0.2$ & 1.30 & 1.00 & N/A & 291 & 448 & 345 & 24.7 & $\mathrm{R}$ & Yes & No \\
\hline 11 & 65 & $\mathrm{~F}$ & OS & $\mathrm{C}_{3} \mathrm{~F}_{8} 0.2$ & 0.70 & 0.82 & 0.40 & 226 & 364 & N/A & 16.7 & $\mathrm{~N} / \mathrm{A}$ & Yes & No \\
\hline 12 & 56 & $\mathrm{~F}$ & OS & $\mathrm{C}_{3} \mathrm{~F}_{8} 0.2$ & 1.30 & 0.00 & N/A & 236 & 440 & 220 & 21.8 & $\mathrm{R}$ & Yes & Yes \\
\hline 13 & 47 & $\mathrm{~F}$ & OD & $\mathrm{C}_{3} \mathrm{~F}_{8} 0.2$ & 0.40 & 0.70 & 0.00 & 341 & 494 & 417 & 17.2 & 1.7 & No & No \\
\hline 14 & 50 & $\mathrm{~F}$ & OD & $\mathrm{C}_{3} \mathrm{~F}_{8} 0.2$ & 0.70 & 0.30 & 0.05 & 271 & 362 & 362 & 25.2 & $\mathrm{R}$ & Yes & Re-open \\
\hline 15 & 61 & $\mathrm{~F}$ & OD & $\mathrm{C}_{3} \mathrm{~F}_{8} 0.1$ & 0.82 & 0.82 & 0.00 & 194 & 339 & $\mathrm{~N} / \mathrm{A}$ & 15.9 & N/A & Yes & No \\
\hline 16 & 72 & $\mathrm{~F}$ & OS & $\mathrm{C}_{3} \mathrm{~F}_{8} 0.1$ & 1.52 & 1.52 & 0.00 & 394 & 365 & 262 & 20.6 & 0.3 & No & No \\
\hline 17 & 54 & $\mathrm{M}$ & OD & $\mathrm{C}_{3} \mathrm{~F}_{8} 0.2$ & 1.30 & 2.00 & 0.10 & 355 & 404 & 314 & 28.4 & 9.1 & Yes & No \\
\hline 18 & 49 & $\mathrm{~F}$ & OS & $\mathrm{C}_{3} \mathrm{~F}_{8} 0.2$ & 0.70 & 0.82 & N/A & 219 & 332 & 320 & 23.3 & 13.0 & Yes & No \\
\hline 19 & 53 & $\mathrm{~F}$ & OD & $\mathrm{C}_{3} \mathrm{~F}_{8} 0.2$ & 0.52 & 0.52 & 0.10 & 179 & 388 & $\mathrm{~N} / \mathrm{A}$ & 25.9 & N/A & Yes & No \\
\hline 20 & 64 & $\mathrm{M}$ & OD & $\mathrm{C}_{3} \mathrm{~F}_{8} 0.15$ & 0.70 & 0.82 & 0.40 & 288 & 337 & $\mathrm{~N} / \mathrm{A}$ & 21.0 & N/A & Yes & No \\
\hline 21 & 61 & $\mathrm{M}$ & OS & $\mathrm{SF}_{6} 0.15$ & 0.70 & 0.70 & N/A & 116 & 251 & 273 & 17.7 & 16.3 & No & Yes \\
\hline
\end{tabular}

FTMH, full-thickness macular hole; BCVA, best-corrected visual acuity; PPV, pars plana vitrectomy; POD1, postoperative day 1;

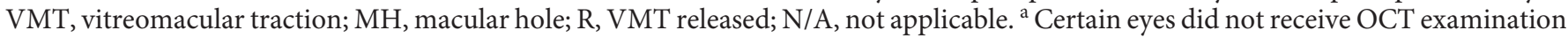
on the first postoperative day, so the data was not applicable in these cases.

to $0.08 \pm 0.06 \log$ MAR in the primary success cases. The treatment course of the impending $\mathrm{MH}$ group is summarized in Figure 1.

All 8 cases in the impending $\mathrm{MH}$ group received OCT examination on postoperative day 1 , and 4 cases already had VMT resolution (Fig. 2). In the 4 cases where VMT persisted, the vitreofoveal angle became flattened in 3 cases (Fig. 3), and became elevated in 1 case (Fig. 4). The postoperative change in the vitreofoveal angle was consistent with the change in the height of retinal elevation except in 1 case, which showed minimal change in the height of retinal elevation (from 343 to $351 \mu \mathrm{m}$, or $2.3 \%$
Vitreomacular Changes after Intravitreal Gas for Impending and Early $\mathrm{MH}$
Ophthalmologica 2018;239:1-10 DOI: $10.1159 / 000478666$ 


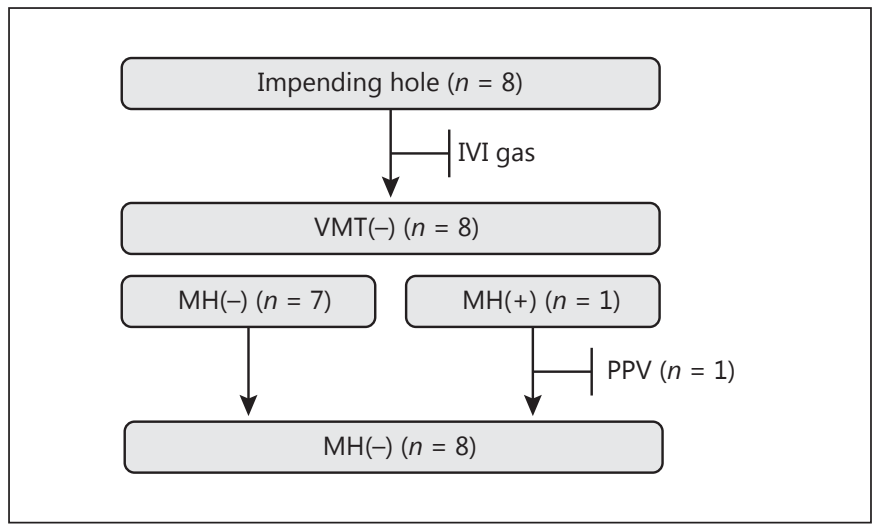

Fig. 1. Schematic diagram on the treatment course of the impending macular hole group. $\mathrm{MH}$, macular hole; IVI, intravitreal injection; VMT, vitreomacular traction; PPV, pars plana vitrectomy.

of baseline), compared with the change in the vitreofoveal angle (from 15.6 to $10.8^{\circ}$, or $30.8 \%$ of baseline). The pre- and postoperative OCT features are summarized in Table 1. Furthermore, we observed that the preoperative vitreofoveal angle was steeper in the elevated case than that in other cases. Increased height of foveal detachment and transient subfoveal fluid pocket were noted after gas injection in the elevated case. Overall, restoration of EZ integrity was achieved in 7 cases (medium time to restoration: 2 months; range: $0.5-6$ months).

\section{Early or Stage 2 FTMH}

The mean $\mathrm{MH}$ diameter was $248.5 \pm 82.4 \mu \mathrm{m}$. In this group, 10 out of 13 cases $(76.9 \%)$ had VMT resolution after intravitreal gas injection, and 3 cases had $\mathrm{MH}$ closure subsequently. However, 1 case developed rhegmatogenous retinal detachment and recurrent $\mathrm{MH}$ 4 months after gas injection (Fig. 5). In 3 cases of persistent VMT, 1 case showed loosening of the traction, and MH spontaneously closed on postoperative day 4 (Fig. 6). The primary success rate was $3 / 13(23.1 \%)$. The mean size of $\mathrm{MH}$ was significantly smaller in the primary success cases compared with the other cases $(157.3 \pm 39.4$ vs. $275.8 \pm 22.8 \mu \mathrm{m}, p=0.0283$ by $t$ test). Surgical vitrectomy was performed in 7 cases of persisted $\mathrm{MH}$ and 1 case of recurrent $\mathrm{MH}$ with rhegmatogenous retinal detachment. $\mathrm{MH}$ was sealed in all cases after vitrectomy, and the mean BCVA was improved from $0.92 \pm 0.35$ to $0.17 \pm 0.23$ logMAR in primary and secondary success cases. The treatment course of the early FTMH group is summarized in Figure 7.
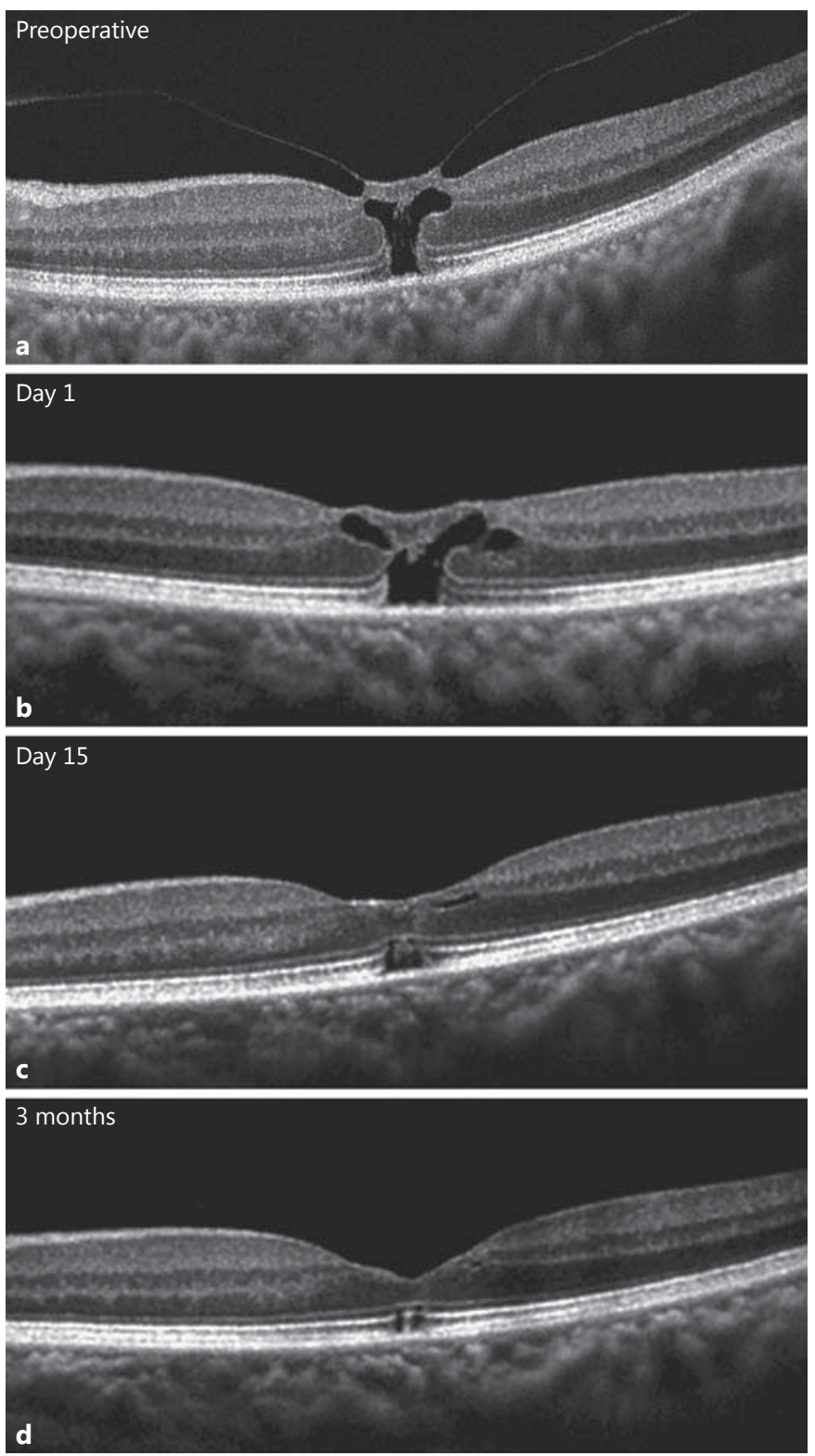

Fig. 2. Serial optical coherence tomography images of case 7 before and after the intravitreal injection of $\mathrm{C}_{3} \mathrm{~F}_{8}$. a Focal vitreomacular traction (VMT) with outer and inner retina dehiscence was observed preoperatively. b On postoperative day 1, VMT released with the flattening of retinal configuration and decreased central foveal thickness was noted. c At 2 weeks postoperatively, minimal intraretinal cyst and mild ellipsoid zone separation were still observed. d At 3 months postoperatively, improvement of ellipsoid zone integrity and foveal contour were noted.

Eight cases in the early FTMH group were evaluated with OCT on postoperative day 1. Three cases had VMT resolution, and 5 cases presented with persistent VMT. Of these 5 cases, all showed flattening of the vitreomacu- 

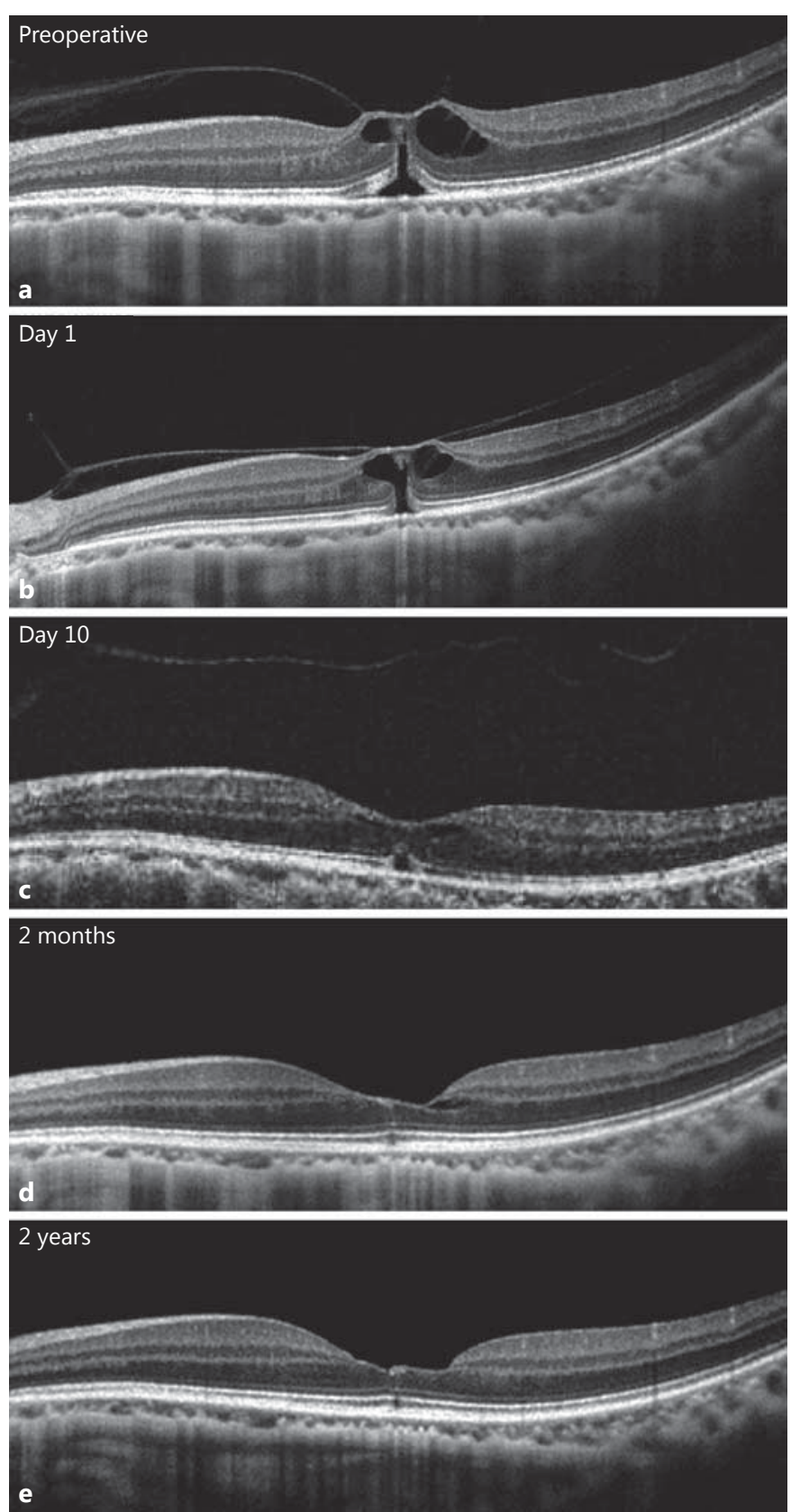

Fig. 3. Serial optical coherence tomography images of case 4 before and after the intravitreal injection of $\mathrm{C}_{3} \mathrm{~F}_{8}$. a Vitreomacular traction (VMT) with intraretinal cysts, impending macular hole, and mild foveal detachment were observed preoperatively. b On postoperative day 1 , flattening of the posterior vitreous cortex and reattachment of the foveal floor were noted. c On postoperative day 10, VMT was released with only mild intraretinal cysts and ellipsoid zone disruption. d, e Restoration of normal foveal contour and ellipsoid zone integrity were achieved during follow-up.
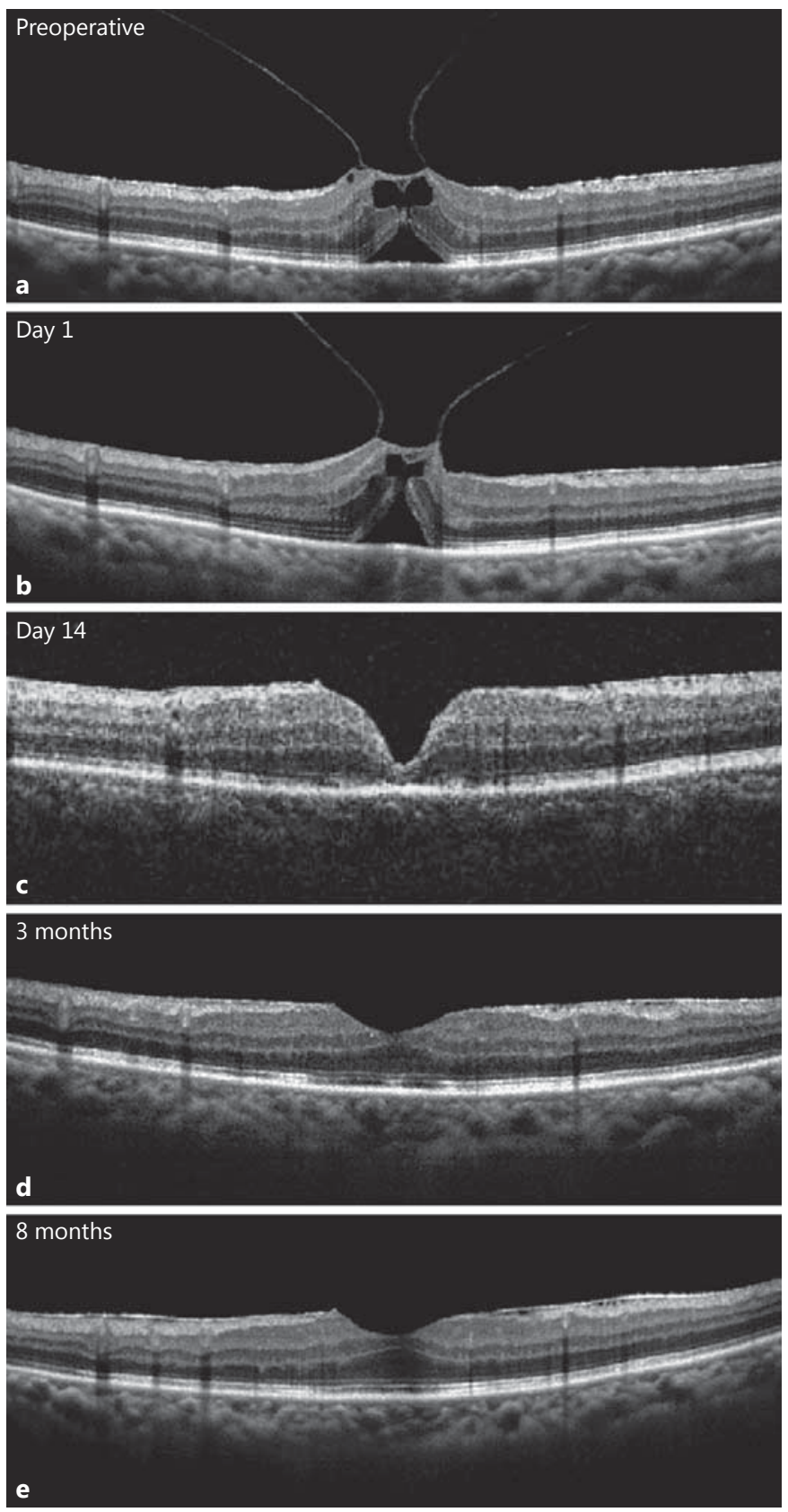

Fig. 4. Serial optical coherence tomography images of case 5 before and after the intravitreal injection of $\mathrm{C}_{3} \mathrm{~F}_{8}$. a Vitreomacular traction (VMT) with intraretinal cysts, impending macular hole, and foveal detachment were observed preoperatively. $\mathbf{b}$ On postoperative day 1, elevation of VMT and rise of foveal detachment were noted. c On postoperative day 14, VMT release and fovea detachment resolved. d Restoration of normal foveal contour and ellipsoid zone integrity were achieved. Epiretinal membrane became more apparent during the follow-up period.
Vitreomacular Changes after Intravitreal Gas for Impending and Early $\mathrm{MH}$
Ophthalmologica 2018;239:1-10 DOI: $10.1159 / 000478666$ 

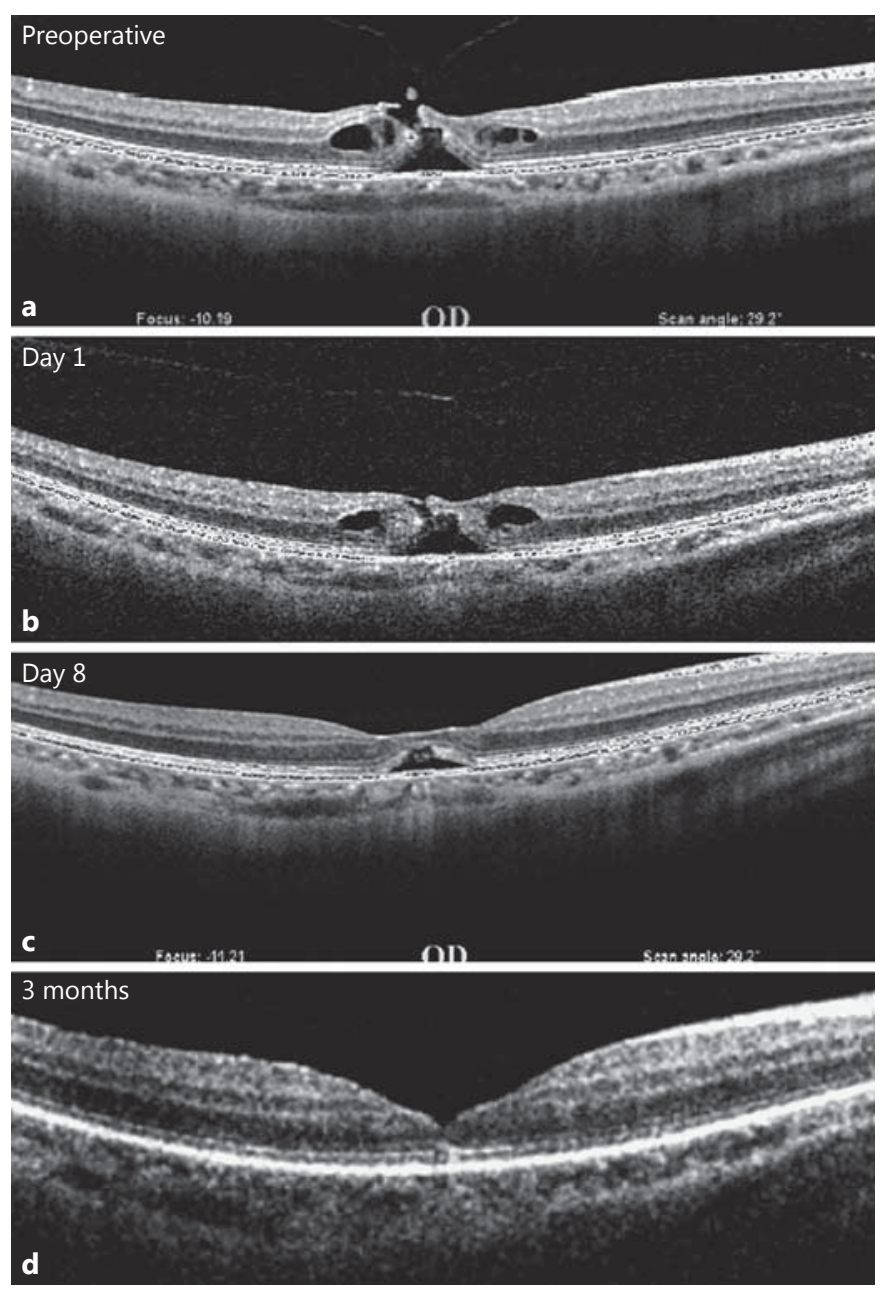

Fig. 5. Serial optical coherence tomography images of case 15 before and after the intravitreal injection of $\mathrm{SF}_{6}$. a Vitreomacular traction (VMT) with small full-thickness macular hole $(\mathrm{MH})$ and intraretinal cysts were observed preoperatively. b On postoperative day 1 , VMT was released and vitreomacular configuration became flattened. c On postoperative day $8, \mathrm{MH}$ had sealed and residual subfoveal fluid pocket was observed. d At 3 months postoperatively, restoration of ellipsoid zone integrity and normal foveal contour were achieved. In this case, recurrent $\mathrm{MH}$ with rhematogenous retinal detachment developed at 4 months postoperatively, and $\mathrm{MH}$ sealed after subsequent pars plana vitrectomy with internal limiting membrane peeling.

lar configuration (Fig. 8). The changes in vitreofoveal angle and height of retinal elevation on postoperative day 1 are listed in Table 2. Four of the 5 cases had later separation of VMT, and 1 showed spontaneous MH closure. During the course of spontaneous $\mathrm{MH}$ closure in the 3 cases, residual subfoveal fluid pockets were observed, and the restoration of EZ on OCT images was achieved in all
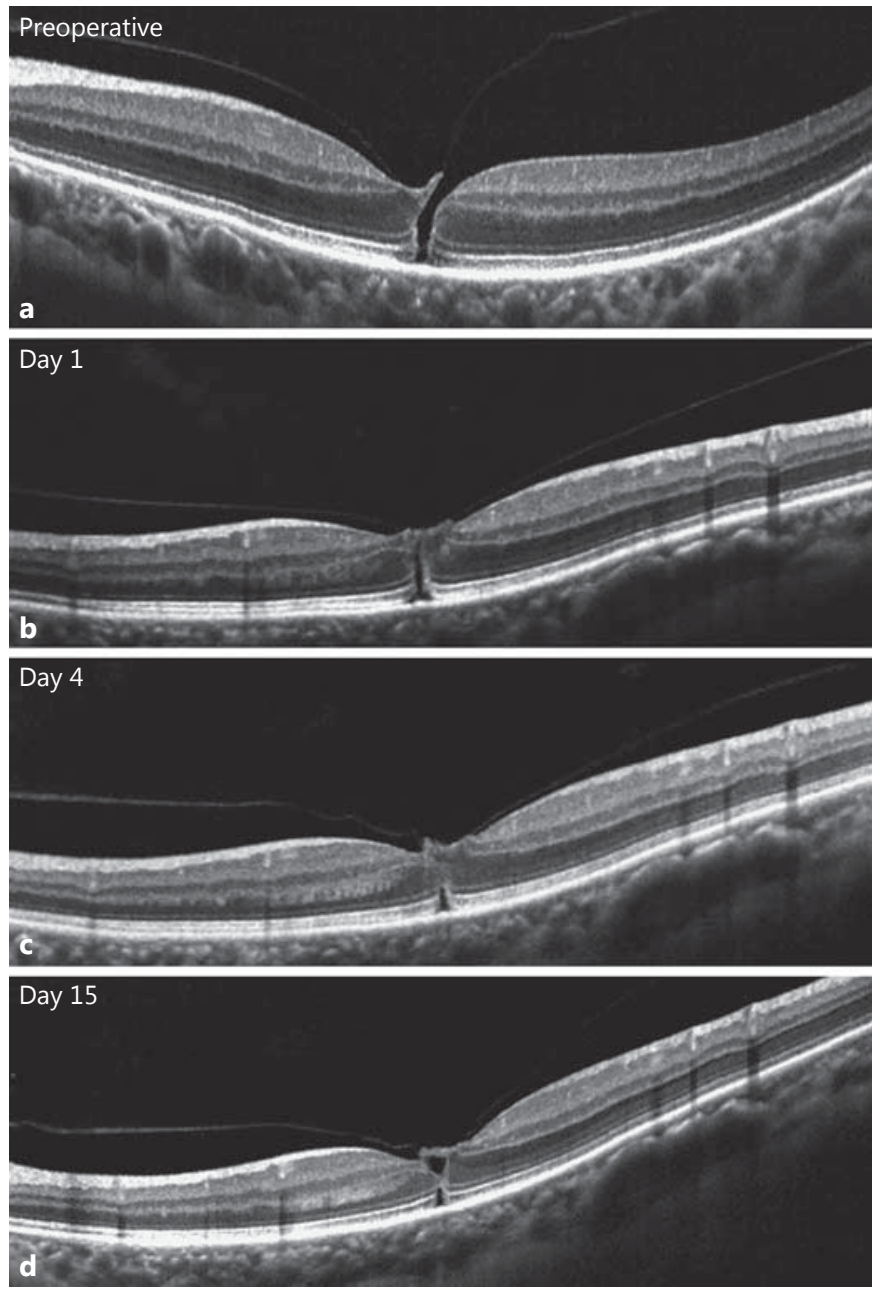

Fig. 6. Serial optical coherence tomography images of case 21 before and after the intravitreal injection (IVI) of $\mathrm{SF}_{6}$. a Vitreomacular traction (VMT) with small full-thickness macular hole (MH) was observed preoperatively. b On postoperative day 1 , flattening of posterior vitreous cortex was noted. c On postoperative day 4, VMT was not released but MH sealed spontaneously. d Fifteen days after IVI gas, VMT persisted despite MH closure.

cases. On the other hand, progression of $\mathrm{MH}$ was found in 4 cases even after VMT resolution. Surgical vitrectomy was performed in these cases and all MHs were sealed successfully.

\section{Discussion}

Our study indicated that intravitreal gas injection was able to induce VMT separation and the subsequent normalization of foveal configuration in an impending $\mathrm{MH}$.

\author{
(D) $10.1159 / 00048666$
}




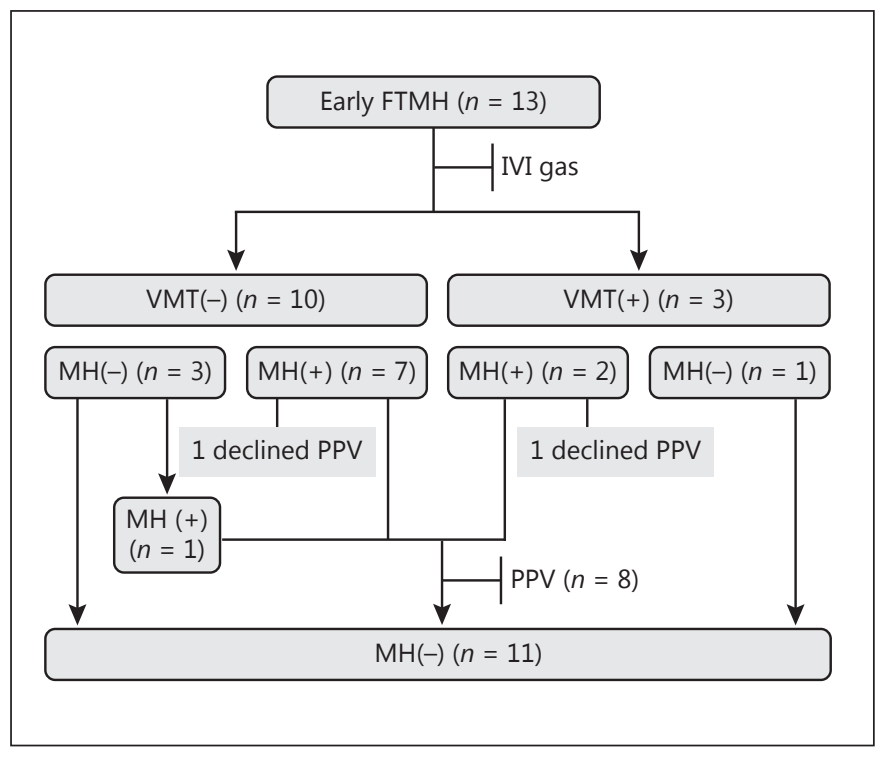

Fig. 7. Schematic diagram on treatment course of the early fullthickness macular hole (FTMH) group. FTMH, full-thickness macular hole; IVI, intravitreal injection; VMT, vitreomacular traction, $\mathrm{MH}$, macular hole; PPV, pars plana vitrectomy.

Overall, 18 of 21 cases (85.7\%) in our study had release of VMT within 1 month after intravitreal gas injection. We performed gas injection to treat impending $\mathrm{MH}$ only in those with definite outer retinal abnormalities, such as foveal detachment or outer lamina disruption. We excluded eyes with only inner retinal changes or minor outer retinal abnormality because such subtle changes may be subject to individual judgement, and these cases tend to be stable over time and may go through spontaneous resolution [21]. Our results were compatible with other studies as summarized in Table 3 [1-8]. Rodrigues et al. [2] analyzed the pretreatment SD-OCT features associated with a higher VMT resolution rate, and found that eyes with a lower horizontal length of vitreomacular adhesion, lower maximum foveal thickness $(<500 \mu \mathrm{m})$, and lower vitreous face reflectivity had higher success rates. The treatment was less effective in VMT associated with age-related macular degeneration or diabetic macular edema than idiopathic VMT. Our series only included cases of idiopathic VMT, and all eyes had focal VMT with maximal foveal thickness $<500 \mu \mathrm{m}$ and low vitreous face reflectivity. We demonstrated that VMT release could be achieved in a high percentage of cases, regardless of foveal thickness. Recently, Claus et al. [7] reported a high VMT release rate by intravitreal $\mathrm{C}_{2} \mathrm{~F}_{6}$ or $\mathrm{SF}_{6}$ injection, with 1 out of 20 eyes developed FTMH subsequently.

Vitreomacular Changes after Intravitreal Gas for Impending and Early $\mathrm{MH}$
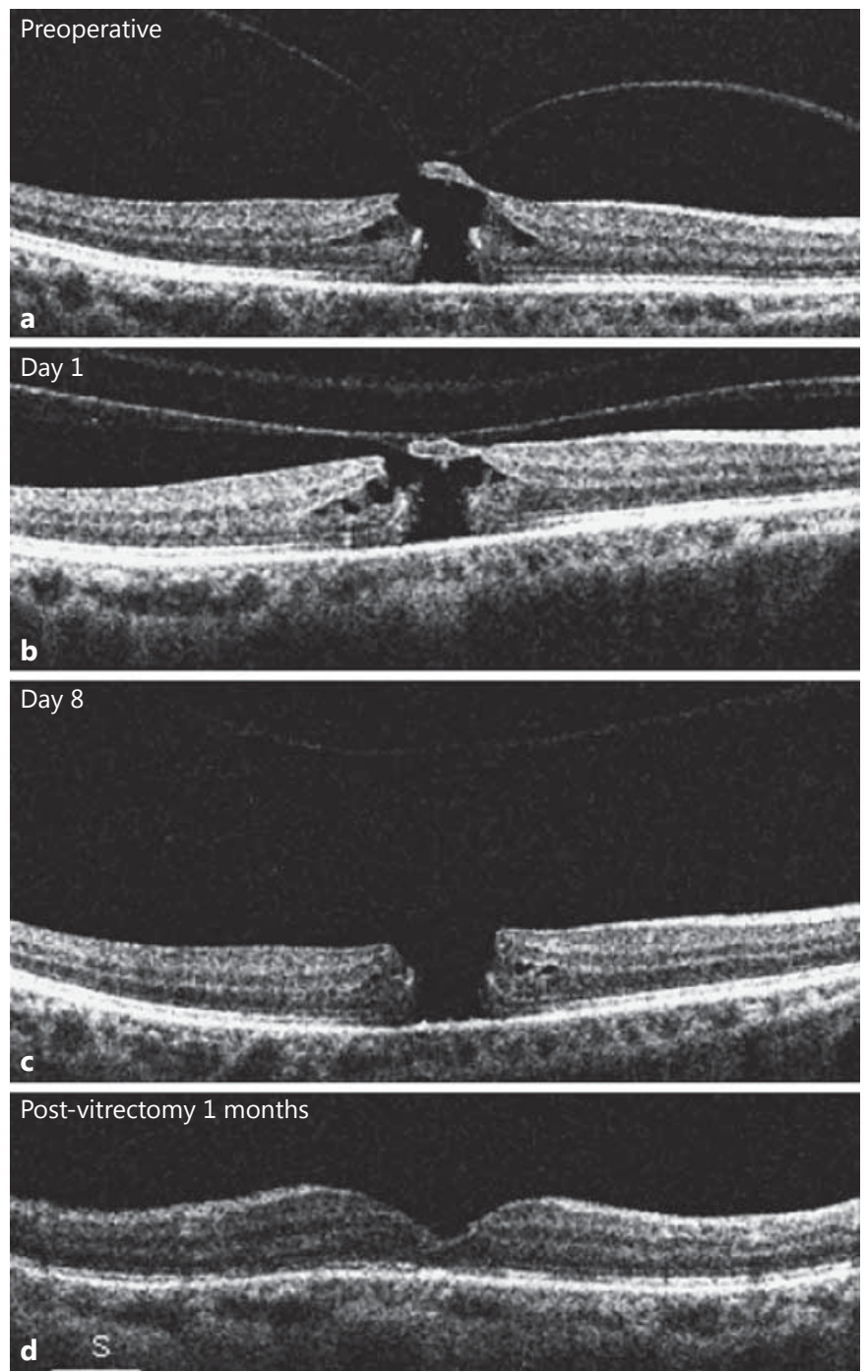

Fig. 8. Serial optical coherence tomography images of case 18 before and after the intravitreal injection of $\mathrm{C}_{3} \mathrm{~F}_{8}$. a Vitreomacular traction (VMT) with small full-thickness macular hole (MH) and intraretinal cysts were observed preoperatively. b On postoperative day 1 , flattening of the posterior vitreous cortex was noted. c On postoperative day 8, VMT was released but $\mathrm{MH}$ enlarged. d One month after surgical vitrectomy, $\mathrm{MH}$ was sealed.

They concluded that the type of gas used has only a minor influence on the result. In our study, we also found that there is no difference in the results between $\mathrm{C}_{3} \mathrm{~F}_{8}$ and $\mathrm{SF}_{6}$.

We observed that the resolution of VMT does not necessarily contribute to the closure of FTMH, and the progression of $\mathrm{MH}$ may continue even after VMT release. In our series, 1 case in the impending $\mathrm{MH}$ group developed FTMH after VMT resolution, and 4 cases in the early FTMH group had enlarged MH sizes after the release of

Ophthalmologica 2018;239:1-10 DOI: $10.1159 / 000478666$ 
Table 3. Outcome of intravitreal gas injection for macular holes (review of recent literature)

\begin{tabular}{|c|c|c|c|}
\hline Reference & VMT release rate & MH closure rate ${ }^{\mathrm{a}}$ & Other comments \\
\hline $\begin{array}{l}\text { Chan et al. [6] } \\
1995\end{array}$ & $18 / 19(94.7 \%)$ & $\begin{array}{l}\text { IMH: 10/11 } \\
\text { Stage } 2 \text { FTMH: } 3 / 6 \\
\text { Stage } 3 \text { FTMH: 0/2 }\end{array}$ & No major complications \\
\hline $\begin{array}{l}\text { Jorge et al. [5] } \\
2006\end{array}$ & $6 / 6(100 \%)$ & Stage 2 FTMH: 5/6 & $\begin{array}{l}\text { Residual hyporeflective area beneath } \\
\text { the fovea }\end{array}$ \\
\hline $\begin{array}{l}\text { Mori et al. [4] } \\
2007\end{array}$ & $19 / 20(95 \%)$ & Stage 2 FTMH: 10/20 & $\begin{array}{l}\text { Inclusion criteria: initial VA }>20 / 40 \text {, } \\
\text { size }<200 \mu \mathrm{m}\end{array}$ \\
\hline $\begin{array}{l}\text { Chen et al. [3] } \\
2012\end{array}$ & $6 / 12(50 \%)$ & Stage 2 FTMH: 3/12 & $\begin{array}{l}\text { FTMH re-opened in } 1 \text { case, RRD in } 2 \\
\text { cases }\end{array}$ \\
\hline $\begin{array}{l}\text { Day et al. [1] } \\
2016 \\
\text { (Studies below only in }\end{array}$ & $\begin{array}{l}5 / 9(55.6 \%) \\
\text { cluded eyes with IN }\end{array}$ & $\begin{array}{l}\text { Stage } 2 \text { FTMH: } 2 / 2 \\
(H)\end{array}$ & $\begin{array}{l}\text { Decreased mean central subfield } \\
\text { thickness }\end{array}$ \\
\hline $\begin{array}{l}\text { Rodrigues et al. [2] } \\
2013\end{array}$ & $6 / 15(40 \%)$ & \multicolumn{2}{|c|}{$\begin{array}{l}\text { Normalization of foveal contour: } 7 / 15(47 \%) \\
\text { Decreased maximal foveal thickness in success cases }\end{array}$} \\
\hline Steinle et al. [8] 2017 & $25 / 30(83.3 \%)$ & \multicolumn{2}{|c|}{$\begin{array}{l}\text { EZ changes on SD-OCT in } 1 \text { case } \\
5 / 6(83.3 \%) \text { eyes with concurrent ERM had VMT released }\end{array}$} \\
\hline $\begin{array}{l}\text { Claus et al. [7] } \\
2017\end{array}$ & $17 / 20(85.0 \%)$ & \multicolumn{2}{|c|}{ Stage 2 FTMH developed in 1 case } \\
\hline
\end{tabular}

VMT, vitreomacular traction; $\mathrm{MH}$, macular hole; IMH, impending macular hole; FTMH, full-thickness macular hole; VA, visual acuity; RRD, rhegmatogenous retinal detachment; EZ, ellipsoid zone; SD-OCT, spectral domain optical coherence tomography; ERM, epiretinal membrane. ${ }^{\text {a }}$ The staging of the macular hole was according to the Gass classification.

traction. Similar findings were also observed by other intravitreal gas studies [2-4]. Our results showed unfavorable outcomes of $\mathrm{MH}$ closure with a primary success rate of only $23.1 \%$. Mori et al. [4] demonstrated a higher closure rate (10 out of 20 stage 2 FTMHs) in eyes with baseline vision better than $0.3 \log$ MAR and a hole diameter $<200 \mu \mathrm{m}$. We observed a similar finding regarding the hole size. Yet, we did not see a relationship between baseline vision and $\mathrm{MH}$ closure rate $(p=0.3554$ by $t$ test), probably because the preoperative BCVA of our early FTMH group was poor (mean of $0.92 \pm 0.35 \log$ MAR), which might partially explain the poor outcomes in our study. Paradoxically, MH closure may be achieved even under persistent VMT. The exact relationship between VMT and MH still needs to be further established.

In this study, we found two patterns of changes after gas injection: the flattening and steepening of the vitreomacular configuration. When the gas bubbles were in the vitreous cavity, assuming a face-down position might push the gas against the posterior hyaloid in the macular area, thus promote the flattening of the vitreomacular configuration. The cause for the steepening of the vitreomacular configuration was more difficult to understand. We noticed that the baseline vitreofoveal angle was steeper in the case that had elevated vitreomacular configuration after gas injection than that in the cases with flattened patterns. It was possible that the higher separation of the posterior hyaloid and the retina left some room for some of the gas bubbles to enter the mid-peripheral subhyaloid space, instead of staying only in the intravitreal space. This condition in turn increased the anterior-posterior vitreous traction on the fovea, resulting in the steepening of the configuration. Regardless of the patterns, the configuration change indicated a disturbance of the vitreomacular interface, and predisposed the eye to the release of VMT. Furthermore, the elevated pattern likely increased traction on the fovea more than the flattening pattern did, which may potentially cause more disruption on macular structure and lead to the development and progression of FTMH. In the early FTMH group, 8 out of 13 cases had OCT done on postoperative day 1. Three cases already presented with VMT separation. The other Ophthalmologica 2018;239:1-10
DOI: $10.1159 / 000478666$
Tew/Chen/Yang/Yang 
5 cases showed unanimous flattening of the foveal contour. Does this mean that the flattening pattern is more likely to occur than the elevation pattern? Our small number of cases makes it difficult to arrive at a definite answer. One alternative explanation is that an elevation pattern may be more likely to lead to an enlargement of the hole and thus, progression of the $\mathrm{MH}$.

Recently, intravitreal ocriplasmin, a chemical vitreolysis agent, has been introduced for the treatment of VMT syndrome, with a $26.5 \%$ VMT resolution rate and $40.6 \%$ nonsurgical $\mathrm{MH}$ closure rate as shown by the MIVITRUST Group [12]. In contrast, treatment of early FTMH with intravitreal gas injection seems discouraging in our study. Steel et al. [22] recently showed that MHs with a narrower base configuration relative to the minimum linear diameter had a higher closure rate when treated with ocriplasmin. Due to the small number of cases, we could not verify the relationship between the $\mathrm{MH}$ configuration and success rate in the current study. Similar to our study, the MIVI-TRUST Trials also observed MH closure in eyes with persisted VMT after ocriplasmin treatment [11] and vice versa, i.e., VMT resolution does not assure the closure of $\mathrm{MH}$ in either treatment. Chatziralli et al. [15] found that the vitreofoveal angle increased initially in the first week after ocriplasmin injection before release of the VMT. Narrowing of the area of vitreomacular adhesion $[23,24]$ and gradual contraction and loosening of the hyaloid in SD-OCT [16] have also been noticed after ocriplasmin injection. These were different from the effect of intravitreal gas in which both flattening and steepening of the foveal configuration could be observed. Besides the changes at the vitreomacular interface, several alterations of the outer retina in SD-OCT after ocriplasmin treatment have also been described, including a transient attenuation or disruption of the EZ, and an accumulation of subfoveal fluid that extends to the parafoveal area [13, $14,16,17,24-26]$. These OCT findings are evidence of the proteolytic activity of ocriplasmin against the adhesion molecules within the vitreoretinal structures, whereas the mechanical force may be the major mechanism of VMT release with the use of gas.

The limitations of our study include the small number of cases and the short follow-up periods for some cases. However, instead of focusing on the efficacy of gas in the treatment of impending or early idiopathic $\mathrm{MH}$, which has already been well documented by other studies, we focused on the early vitreomacular changes after gas injection in order to better understand the possible mechanism of VMT resolution. We noticed that the vitreomacular configuration might be elevated or flattened before traction was released, and we proposed that this disturbance of the vitreomacular interface predisposed the eye to the mechanical release of VMT. We proposed that, early after gas injection, the traction on macula transiently increases, especially in eyes that show the elevated pattern. Caution should be taken especially in the eyes with steeper baseline vitreofoveal angle. In conclusion, because of the high success rate of gas injection for impending $\mathrm{MH}$, we suggest that intravitreal gas may be a useful option as an initial treatment. Unfortunately, the same conclusion cannot be reached for early FTMH, since we found that the release of VMT did not guarantee the closure of early FTMH, especially with a hole size $>200 \mu \mathrm{m}$. Therefore, we do not suggest performing intravitreal gas injection for the treatment of early FTMH.

\section{Disclosure Statement}

The authors have no financial interest in any materials or equipment used in the study.

\section{References}

1 Day S, Martinez JA, Nixon PA, Levitan M, Dooner JW, Wong RW, Harper CA 3rd: Intravitreal sulfur hexafluoride injection for the treatment of vitreomacular traction syndrome. Retina 2016;36:733-737.

2 Rodrigues IA, Stangos AN, McHugh DA, Jackson TL: Intravitreal injection of expansile perfluoropropane $(c(3) f(8))$ for the treatment of vitreomacular traction. Am J Ophthalmol 2013;155:270-276.e2.

3 Chen TC, Yang CH, Yang CM: Intravitreal expansile gas in the treatment of early macular hole: reappraisal. Ophthalmologica 2012; 228:159-166.

Vitreomacular Changes after Intravitreal Gas for Impending and Early $\mathrm{MH}$
4 Mori K, Saito S, Gehlbach PL, Yoneya S: Treatment of stage 2 macular hole by intravitreous injection of expansile gas and induction of posterior vitreous detachment. Ophthalmology 2007;114:127-133.

5 Jorge R, Costa RA, Cardillo JA, Uno F, Bonomo PP, Farah ME: Optical coherence tomography evaluation of idiopathic macular hole treatment by gas-assisted posterior vitreous detachment. Am J Ophthalmol 2006;142: 869-871.

6 Chan CK, Wessels IF, Friedrichsen EJ: Treatment of idiopathic macular holes by induced posterior vitreous detachment. Ophthalmology 1995;102:757-767.
7 Claus MG, Feron E, Veckeneer M: Pneumatic release of focal vitreomacular traction. Eye (Lond) 2017;31:411-416.

8 Steinle NC, Dhoot DS, Quezada Ruiz C, Castellarin AA, Pieramici DJ, See RF, Couvillion SC, Nasir MA, Avery RL: Treatment of vitreomacular traction with intravitreal perfluoropropane (c3f8) injection. Retina 2017;37:643650.

9 Sharma P, Juhn A, Houston SK, Fineman M, Chiang A, Ho A, Regillo C: Efficacy of intravitreal ocriplasmin on vitreomacular traction and full-thickness macular holes. Am J Ophthalmol 2015;159:861-867.e2. 
10 Haller JA, Stalmans P, Benz MS, Gandorfer A, Pakola SJ, Girach A, Kampik A, Jaffe GJ, Toth CA, Group M-TS: Efficacy of intravitreal ocriplasmin for treatment of vitreomacular adhesion: subgroup analyses from two randomized trials. Ophthalmology 2015;122: 117-122.

11 Dugel PU, Regillo C, Eliott D: Characterization of anatomic and visual function outcomes in patients with full-thickness macular hole in ocriplasmin phase 3 trials. Am J Ophthalmol 2015;160:94-99.e1.

12 Stalmans P, Benz MS, Gandorfer A, Kampik A, Girach A, Pakola S, Haller JA, Group M-TS: Enzymatic vitreolysis with ocriplasmin for vitreomacular traction and macular holes. N Engl J Med 2012;367:606-615.

13 Nudleman E, Franklin MS, Wolfe JD, Williams GA, Ruby AJ: Resolution of subretinal fluid and outer retinal changes in patients treated with ocriplasmin. Retina 2016;36: 738-743.

14 Itoh Y, Ehlers JP: Ellipsoid zone mapping and outer retinal characterization after intravitreal ocriplasmin. Retina 2016;36:2290-2296.

15 Chatziralli I, Theodossiadis G, Parikakis E, Datseris I, Theodossiadis P: Real-life experience after intravitreal ocriplasmin for vitreomacular traction and macular hole: a spectraldomain optical coherence tomography prospective study. Graefes Arch Clin Exp Ophthalmol 2016;254:223-233.
16 Warrow DJ, Lai MM, Patel A, Raevis J, Berinstein DM: Treatment outcomes and spectraldomain optical coherence tomography findings of eyes with symptomatic vitreomacular adhesion treated with intravitreal ocriplasmin. Am J Ophthalmol 2015;159:20-30.e1.

17 Quezada-Ruiz C, Pieramici DJ, Nasir M, Rabena M, Steinle N, Castellarin AA, Dhoot D, Couvillion S, See RF, Avery RL: Outer retina reflectivity changes on SD-OCT after intravitreal ocriplasmin for vitreomacular traction and macular hole. Retina 2015;35:1144-1150.

18 Gass JD: Reappraisal of biomicroscopic classification of stages of development of a macular hole. Am J Ophthalmol 1995;119:752-759.

19 Duker JS, Kaiser PK, Binder S, de Smet MD, Gaudric A, Reichel E, Sadda SR, Sebag J, Spaide RF, Stalmans P: The international vitreomacular traction study group classification of vitreomacular adhesion, traction, and macular hole. Ophthalmology 2013;120: 2611-2619.

20 Steel DH, Downey L, Greiner K, Heimann H, Jackson TL, Koshy Z, Laidlaw DA, Wickham L, Yang Y: The design and validation of an optical coherence tomography-based classification system for focal vitreomacular traction. Eye (Lond) 2016;30:314-324; quiz 325.

21 John VJ, Flynn HW Jr, Smiddy WE, Carver A, Leonard R, Tabandeh H, Boyer DS: Clinical course of vitreomacular adhesion managed by initial observation. Retina 2014;34:442-446.
22 Steel DH, Parkes C, Papastavrou VT, Avery PJ, El-Ghrably IA, Habib MS, Sandinha MT, Smith J, Stannard KP, Vaideanu-Collins D, Hillier RJ: Predicting macular hole closure with ocriplasmin based on spectral domain optical coherence tomography. Eye (Lond) 2016;30:740-745

23 Jeng KW, Baumal CR, Witkin AJ, Witkin SR, Wiegand TW, Waheed NK: Incomplete release of vitreomacular attachments after intravitreal ocriplasmin. Ophthalmic Surg Lasers Imaging Retina 2015;46:271-274.

24 Meyer JC, Shah GK, Blinder KJ, Waheed NK, Reichel E, Stalmans P, Singer M, Tewari A: Early evolution of the vitreomacular interface and clinical efficacy after ocriplasmin injection for symptomatic vitreomacular adhesion. Ophthalmic Surg Lasers Imaging Retina 2015;46:209-216.

25 Itoh Y, Kaiser PK, Singh RP, Srivastava SK, Ehlers JP: Assessment of retinal alterations after intravitreal ocriplasmin with spectral-domain optical coherence tomography. Ophthalmology 2014;121:2506-2507.e2.

26 Singh RP, Li A, Bedi R, Srivastava S, Sears JE, Ehlers JP, Schachat AP, Kaiser PK: Anatomical and visual outcomes following ocriplasmin treatment for symptomatic vitreomacular traction syndrome. Br J Ophthalmol 2014; 98:356-360. 